\title{
Carlos Pitillas Salvá (2021). \\ El daño que se hereda: comprender y abordar la transmisión transgeneracional del trauma. Desclée Dde Brouwer. 256 páginas
}

\author{
Ana Berástegui \\ Instituto Universitario de la Familia
}

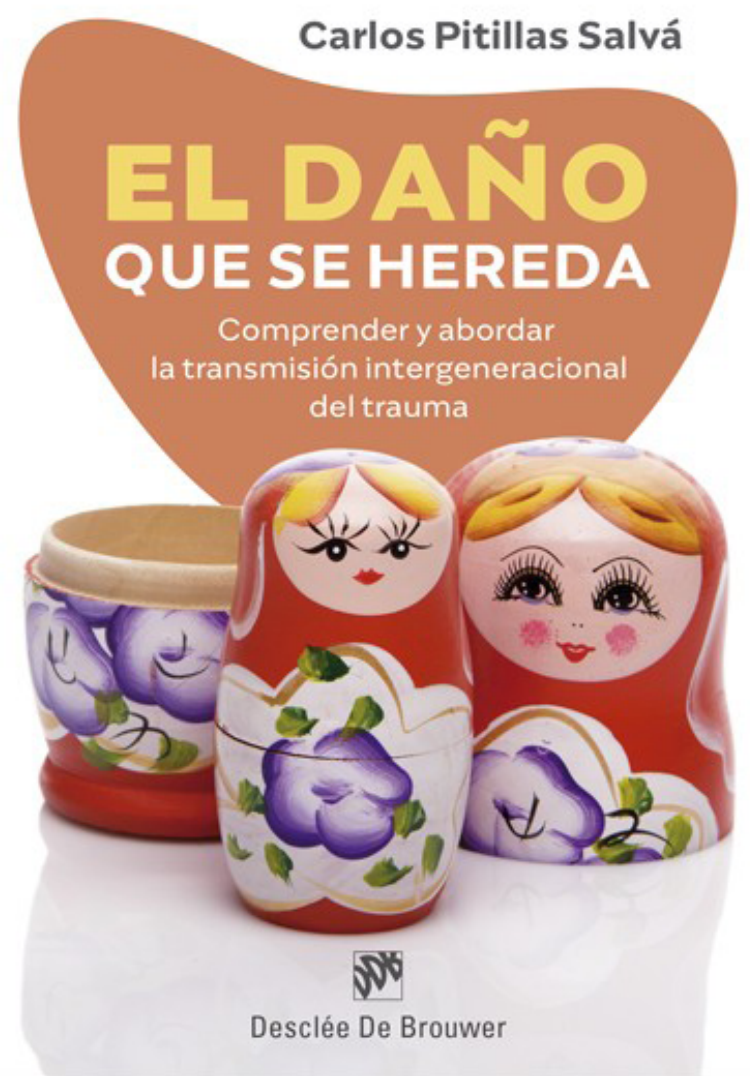

En el trabajo con familias es frecuente constatar que los padres y las madres que tienen dificultades graves para cuidar adecuadamente a sus hijos, vivieron a su vez experiencias de maltrato y negligencia durante su infancia. Las heridas emocionales de los niños, cuando han sido suficientemente intensas y no han podido resolverse, acompañan a la persona hasta la vida adulta, hasta el punto de empujarla a reproducir sobre sus hijos los daños que ellos mismos sufrieron. Ésta es la dolorosa realidad que aborda El daño que se hereda: comprender y abordar la transmisión intergeneracional del trauma, de Carlos Pitillas Salvá.

El autor aborda así, a lo largo de doscientas cincuenta apasionantes páginas, algunas de las preguntas que más preocupan profesionales de la protección infantil, terapeutas de niños y familias, expertos en psicología evolutiva y, también a padres, madres que atravesaron experiencias atemorizantes o dolorosas como niños: ¿Por qué algunos padres dañados se convierten en fuentes de peligro para sus propios hijos? ¿Cómo se reactiva el dolor y el miedo del trauma infantil durante la crianza de los hijos? ¿Qué aspectos de la relación con los hijos se ven afectados por estas experiencias tempranas? Y, lo que es más importante: ¿Qué podemos hacer desde la intervención para ayudar a estos padres y madres a frenar la repetición de sus traumas y desplegar prácticas seguras de crianza?

Este libro propone algunas respuestas para estas y otras preguntas a lo largo de las tres partes en las que se estructura.

La correspondencia sobre este artículo debe enviarse a Ana Berástegui: a.berastegui@comillas.edu

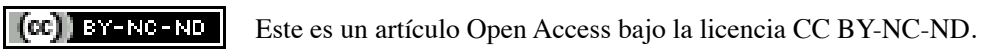


La primera parte (titulada "Los vínculos afectivos al principio de la vida") explora los aspectos esenciales de las relaciones tempranas padres-hijos cuando éstas son seguras y promueven un desarrollo sano. Esta sección ofrece un retrato de la seguridad articulado en cuatro procesos esenciales: los procesos de influencia mutua cuidador-niño; la regulación emocional y fisiológica ejercida por los cuidadores sobre los hijos; las dinámicas de ruptura y reparación en las interacciones padres-hijos; y los procesos de mentalización y especularización parental. El detallado retrato de estas relaciones se basa en los estudios desarrollados desde el nacimiento de la psicología del apego (con los trabajos de Bowlby y Ainsworth) hasta las actuales investigaciones microanalíticas de la interacción madre-bebé.

La segunda parte (titulada “Trauma temprano, desorganización del apego y estrategias de reorganización") hace un recorrido detallado por los procesos que distorsionan las relaciones tempranas padres-hijos, empujándolas hacia la inseguridad o el trauma. Estos procesos se relacionan de maneras diversas con las heridas relacionales no resueltas del cuidador. En el curso de las interacciones con sus hijos, el cuidador herido puede verse asaltado por emociones negativas insoportables, fuertes distorsiones en su interpretación acerca de lo que ocurre, una experiencia intensa de amenaza y, como consecuencia, la necesidad de defenderse del niño. Esta es, tal vez, una de las tesis más centrales del libro: las conductas parentales que dañan a los hijos, en muchos casos, se activan como defensa frente a la sensación de peligro que experimenta el cuidador cuando, en el contacto con el niño, se reactivan aspectos de su propio trauma relacional. Esta sección del libro abunda en referencias de la literatura sobre apego desorganizado, los estudios sobre interacciones madre-bebé, la teoría de la mentalización parental, las perspectivas psicoanalíticas contemporáneas acerca del trauma o el neuropsicoanálisis, entre otros. Tal vez la aportación central de este apartado sea el modelo circular de las relaciones de apego inseguras/traumáticas, donde el malestar tiende a retroalimentarse y crecer de una forma recursiva. En muchos casos, es el niño quien encuentra una salida de estos círculos viciosos, al desplegar estrategias de adaptación al trauma que, a medio y largo plazo, perjudican seriamente su desarrollo.

La última parte del libro (titulada "Fortalecer y reparar las relaciones tempranas: principios y estrategias de intervención centrada en el vínculo") recoge una serie de elementos comunes a las terapias padres-hijos y las intervenciones centradas en el vínculo, proponiendo un modelo de trabajo terapéutico que busca reparar la parentalidad de estos adultos dañados. En su revisión de las propuestas de tratamiento que llevan aplicándose y validándose desde finales de los años 90, el autor concluye que las intervenciones deben realizarse en dos niveles simultáneamente. En un nivel fundamental, la intervención debe incorporar experiencias terapéuticas que devuelvan cierta seguridad emocional a los padres traumatizados. Los ingredientes que componen este "marco de seguridad" descrito por el autor coinciden con los cuatro ingredientes de las relaciones de apego seguras, que el autor ya ha descrito en la primera parte del libro, y que aquí son trasladados al escenario terapéutico y aplicados de una forma que pueda ser relevante para las familias. Este marco de seguridad es condición necesaria para que el resto de las intervenciones sean comprensibles, tolerables y útiles para los padres heridos. El segundo nivel de trabajo incluye las técnicas que promueven una mejora en las competencias parentales. Estas técnicas buscan, por ejemplo, robustecer las habilidades de mentalización parental, transformar positivamente su visión de sí mismos como cuidadores, o reconocer el impacto de su pasado difícil sobre su presente como padres. En esta sección se presentan extractos de diálogos clínicos con padres y madres, así como propuestas específicas de aplicación de los principios terapéuticos descritos.

El autor, combina a lo largo de todo el libro su doble faceta de profesor de Psicología de la Universidad P. Comillas, con su experiencia clínica como terapeuta de niños, adolescente y adultos. Como académico ordena, sintetiza e integra en un marco con sentido una gran cantidad de conocimiento científico que proviene de la psicología del apego, la investigación evolutiva, el psicoanálisis interpersonal y las intervenciones centradas en el vínculo. Como profesor ofrece una traducción accesible para la intervención profesional en diversos ámbitos y para su divulgación entre todos los interesados por el desarrollo infantil y la crianza. Finalmente, su mirada como terapeuta y profesional de la intervención psicosocial ilumina este proceso y permite, a su vez, a que todo este conocimiento científico y técnico se encarne y se haga transferible a la relación con los padres heridos.

Como lectora interesada en el bienestar infantil, especialmente en contextos de riesgo psicosocial, creo que este libro es interesante, es útil y es inspirador: El libro es interesante porque permite comprender mejor y mi- 
rar desde diversas perspectivas un fenómeno clave del desarrollo y de la parentalidad. El libro es útil porque ofrece herramientas concretas, modelos de trabajo y ejemplos que pueden alimentar la práctica de terapeutas, pero también de trabajadores y educadores sociales, profesionales de la salud o de la educación. Finamente, el libro es inspirador porque está atravesado por la capacidad y el compromiso del autor por mirar y escuchar a las familias, atendiendo a su dolor y a sus llamadas de socorro, pero rescatando también sus proyectos y esperanzas de ser mejores padres para sus hijos. Hablar de los padres que Stéfano Cirillo llamó "Malos padres" como pares heridos permite acercarse a la intervención desde la dignidad y la esperanza.

Esta mirada no supone para el autor dejar de poner al niño que sufre y que necesita ser protegido en el centro. Más bien al contrario, ya que, cuando la protección no se acompaña de una experiencia relacional reparadora, aumenta el riesgo de que estos niños y niñas lleguen a la vida adulta sin las herramientas para romper con la transmisión transgeneracional del trauma. Sin embargo, mirar, atender y sostener a los padres heridos, permite restaurar para ellos una oportunidad que no tuvieron de niños, permite a sus hijos reparar a tiempo los daños de una crianza marcada por ese dolor y, finalmente, permite que esos niños puedan ser padres con una herencia de cuidado que transmitir a sus hijos y a los hijos de sus hijos.

Así, la apuesta por el fortalecimiento y la reparación de las relaciones padres-hijos en contextos riesgo psicosocial y de trauma interpersonal temprano, que comparto con el autor en el marco del programa Primera Alianza, y a la que invita la lectura de este libro, no solo es útil para prevenir, detener y tratar los malos tratos de mayor o menor intensidad en los padres actuales, sino que es semilla de buen trato para sus hijos y los hijos de sus hijos, en una cadena de cuidados. Espero que, gracias a la publicación de este libro, cada vez más profesionales del trabajo con niños y familias vulnerables puedan comprender estas dinámicas, abordar sus consecuencias y comprometerse con esta mirada compasiva y esperanzada hacia los niños que fueron dañados en el pasado y los niños que ya no sufrirán daños en el futuro. 